\title{
A Review on Isothiazoles and their Derivatives: Synthesis, Reactions and Pharmaceutical Importance
}

\section{Md. Ashraful Alam¹,2,*, Kazuaki Shimada1, Md. Wahab Khan³, Md.} Delwar Hossain 4

${ }^{1}$ Department of Chemistry and Biological Sciences, Iwate University, Morioka, Japan ${ }^{2}$ Department of Chemistry, International University of Business Agriculture and Technology (IUBAT), Dhaka, Bangladesh

${ }^{3}$ Department of Chemistry, Bangladesh University of Engineering and Technology (BUET), Dhaka, Bangladesh ${ }^{4}$ Department of Chemistry, Jagannath University, Dhaka, Bangladesh

\section{Review Article}

Volume 3 Issue 2

Received Date: March 14, 2019

Published Date: April 30, 2019

DOI: $10.23880 /$ macij-16000137

*Corresponding author: Md. Ashraful Alam, Department of Chemistry and Biological Sciences, Iwate University, Morioka, Japan, Email: sdashraf84@yahoo.com

\begin{abstract}
Isothiazoles are the significant topics of heterocyclic compounds as the heterocyclic system is one of the most important building blocks for new materials possessing interesting electronic, mechanical or biological properties. The isothiazoles also find vast application to search for the alternative synthetic strategies and development of novel molecular structures. The most recent findings in the fields of isothiazoles are described here in a systematic way. Some of the important applications in the pharmaceutical fields are also studied and reported here in this review study. It is desirable that the chemists get the value up to date information from this report regarding the synthesis, reactions and pharmaceutical importance of isothiazoles.
\end{abstract}

Keywords: Isothiazoles; Pharmaceutical Importance; Synthesis; Medicinal importance

\section{Introduction}

Isothiazoles constitute a novel class of heterocyclic compounds. It was revealed a literature [1] survey that isothiazole 1 was first prepared in 1956 successfully and since then its chemical and physical properties have been extensively studied. The chemistry of isothiazoles saw a rapid progress since the 1,2-thiazole (isothiazole) ring was synthesized [2]. The heterocycles of this class of these compounds showed a broad range of useful properties which prompted the researchers to study the synthesis and chemical transformations of its derivatives.
During this time, a number of ways have been discovered for the preparation of different types of isothiazoles and their derivatives. Also, the chemical and physical properties of isothiazole have been extensively studied up to date. Although the study was done by different researchers in various ways, the more concentration should be given to this area as the isothiazoles moiety possess a peculiar reactivity and so it has been considered as useful blocks of synthetic compounds. They also find the application in the search 


\section{Medicinal \& Analytical Chemistry International Journal}

for alternative synthetic strategies and development of novel molecular structures.

Also, many reviews have been published in the literature regarding the chemistry of isothiazoles and their fused derivatives $[3,4]$. Comprehensive reviews and other recent articles on the synthesis and chemistry of isothiazoles have been reported [5-11]. There is also a dissertation about selected features of the chemistry of these types of compounds [12,13]. The structure of isothiazole (A) (1,2-thiazole), isothiazole-1,1-dioxides (sultams) 2, and the two classes of 1,2-benzisothiazole 3 and 2,1-benzisothiazole 4 are shown in Figure 1 [14-20]. The investigation of the chemistry of the synthetic versatility of isothiazole has stemmed also from the interest in the pharmacological as well as the biological properties of its derivatives.

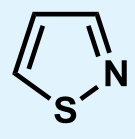

1

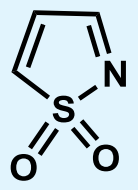

2

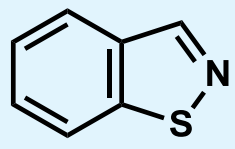

3

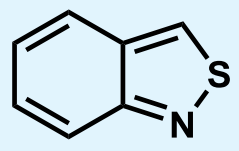

4

Figure 1: Structural features of Isothiazoles.

The compounds of isothiazoles behave as the stable aromatic molecules because of the existence of an aromatic delocalized $\pi$ - electron system. By measuring the ring hydrogen exchange rates for isothiazole, 3-and 5methyl isothiazole derivatives it was found that isothiazole has a small degree of bond fixation, and that the aromaticity of isothiazole was greater than that for pyrazole followed by isoxazole moiety. The aromaticity of the isothiazole ring can also be measured by their nonlocal diamagnetic susceptibility which is perpendicular to the plane of the molecule.

\section{Synthesis and Reactions of Isothiazoles and Their Derivatives}

\section{Synthesis}

Through the oxidation of 5-amino-1,2benzoisothiazole 5 with an alkaline solution of potassium permanganate with subsequent decarboxylation of isothiazole-4,5-dicarboxylic acid 6, the Isothiazole 1 was first prepared (Scheme 1) [21-25]. This type of synthetic procedure has a purely historical significance. Later, isothiazoles were synthesised from simpler and more accessible compounds [26].

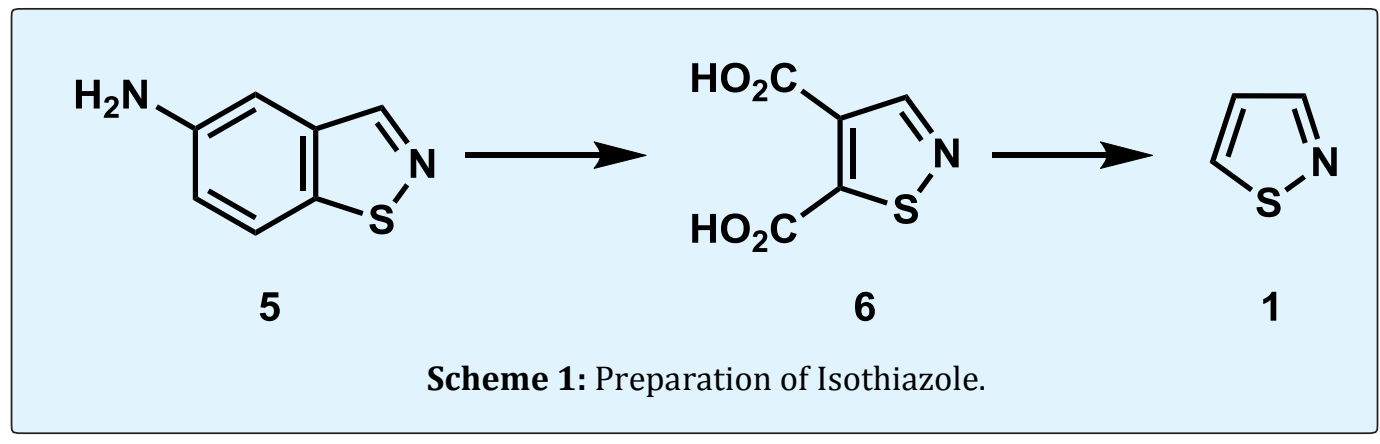

The synthetic methods of isothiazoles using cycloaddition and condensation reactions of compounds containing a set of essential fragments are the mostwellstudied and attract, as before, the attention of investigators. Thus the 1,3-dipolar cycloaddition of nitrile sulfide 7 to dimethyl acetylenedicarboxylate 8 yields the isothiazole derivative 9. This structure has also been confirmed by X-ray diffraction analysis (Scheme 2) [27]. 


\section{Medicinal \& Analytical Chemistry International Journal}

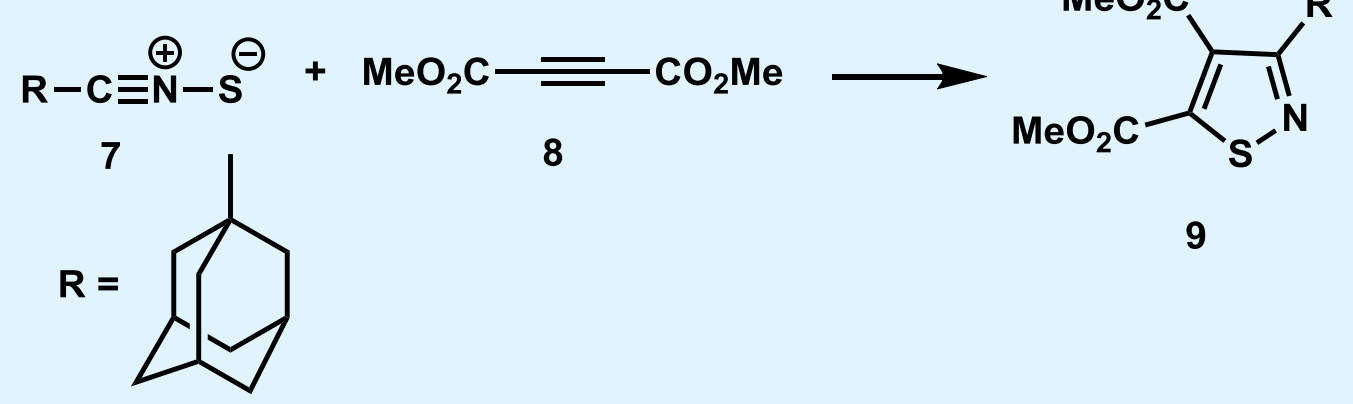

Scheme 2: Synthesis of Isothiazoles derivatives.

For the synthesis of isothiazoles, the usage of 1,3,5trichloro-1,3,5,2,4,6-trithiatriazine 11 seems to be very promising. It was found that ordinary allylic compounds of the type 10 react with the reagent 11 as two-carbon units to give 1,2,5-thiadiazoles 12 and as three-carbon units to give isothiazoles 13 . The ratio of compounds 12 and 13 depends on the reaction conditions and the nature of the substituents (Scheme 3) [28].

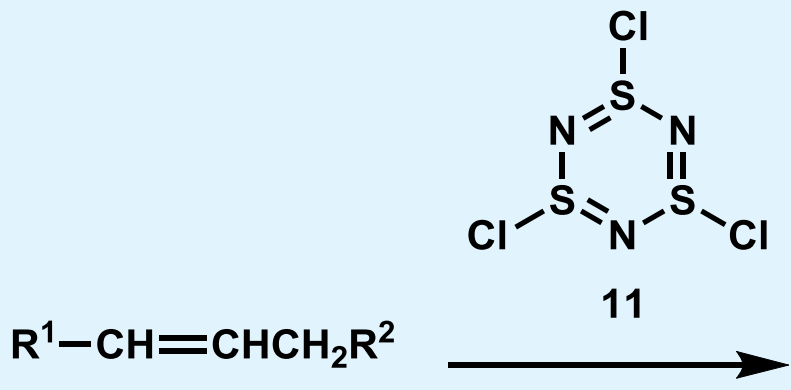

10

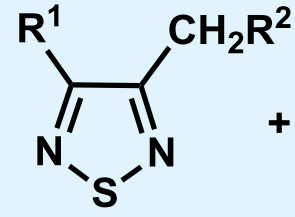

12

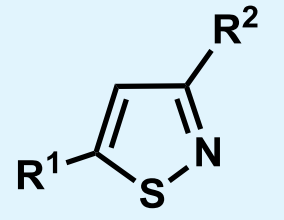

13

Scheme 3: Synthesis of isothiazoles derivatives from ordinary allylic compounds.

For the synthesis of isothiazoles 14 containing fluorosubstituted aryl groups, researcher Schulze et al. [29] have developed two procedures. The first of them is based on the reaction of $\beta$-thiocyana-tocinnamaldehydes 15 with ammonium thiocyanate. Isothiazoles 14 were obtained in good yields. In this case, ammonium thiocyanate acts as a source of ammonium required for ring closure. It is noteworthy that ammonium thiocyanate was employed previously for the preparation of 4- and 5alkylisothiazoles [30]. The second route is based on the use of enamino thiones 16 as starting compounds; their reaction with hydroxylamine-0-sulfonic acid gives isothiazoles 14 (Scheme 4). In this case, the yields reached to $98 \%$. 


\section{Medicinal \& Analytical Chemistry International Journal}

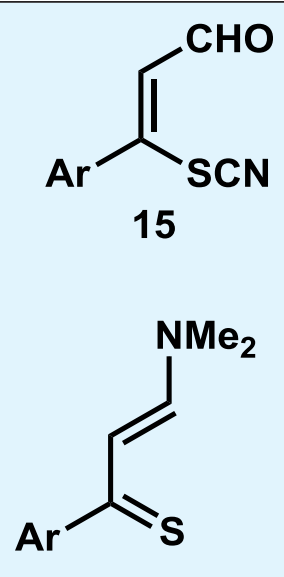

16

\section{$\mathrm{NH}_{4} \mathrm{SCN}$}

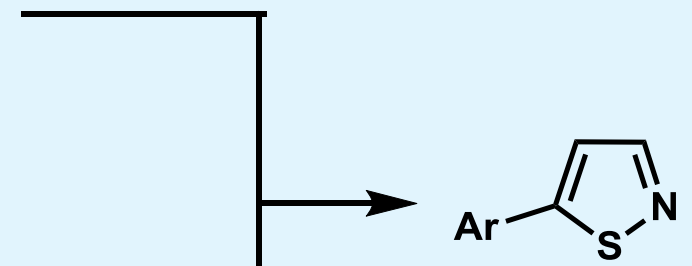

$\mathrm{NH}_{2} \mathrm{OSO}_{3} \mathrm{H}$

14

\section{$\mathrm{Ar}=4-\mathrm{CF}_{3} \mathrm{C}_{6} \mathrm{H}_{4}, 3-\mathrm{CF}_{3} \mathrm{C}_{6} \mathrm{H}_{4}, 3-\mathrm{FC}_{6} \mathrm{H}_{4}$}

Scheme 4: Synthesis of isothiazoles derivatives from $\beta$-thiocyana-tocinnamaldehydes and enamino thiones Synthesis of isothiazoles from some of the heterocyclic compounds.

Methods for the synthesis of substituted isothiazoles from other heterocyclic compounds found wide application despite the fact that they belong to the most ancient ones. Thus 3,5-disubstituted isothiazoles 17 were prepared from isoxazoles 18 through the reaction with phosphorus pentasulfide in pyridine (Scheme 5) [31].

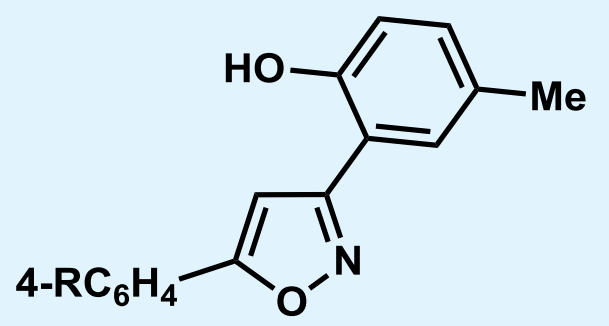

18
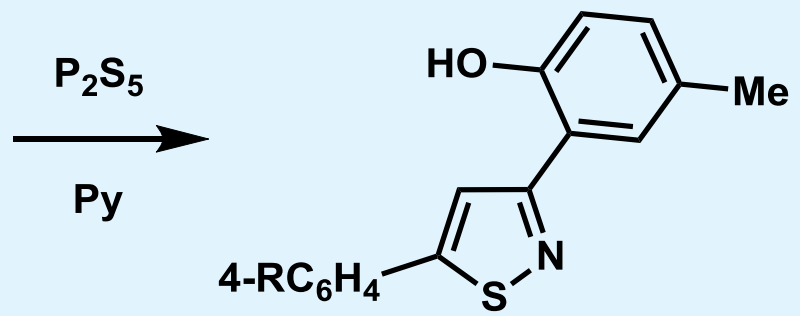

17

Scheme 5: Synthesis of isothiazoles derivatives from isoxazoles.

The reaction of 2-imino-3,4-dihydro-2H-pyrrole 20 with sulfur on heating is accompanied by dehydrogenation and incorporation of the sulfur atom into the pyrrole ring resulting in the previously unknown thiazolylisothiazoles 19 (Scheme 6) [32]. 


\section{Medicinal \& Analytical Chemistry International Journal}

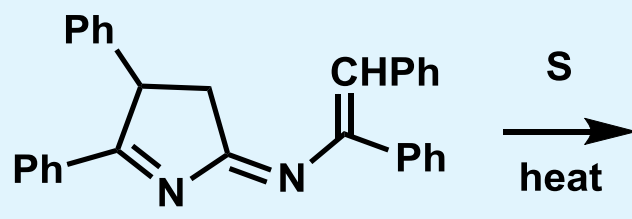

20

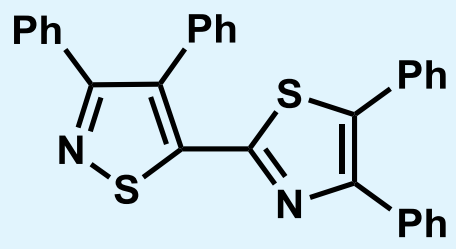

19

Scheme 6: Synthesis of isothiazoles derivatives from 2-imino-3,4-dihydro-2H-pyrrole.

\section{Reactions}

The reactions of isothiazole 1,1-dioxides containing different substituents at C-5 21 with sodium azide in acetonitrile gives the product 22 (Scheme 7).<smiles>[R]C1=NS(=O)(=O)C([R])=C1[Al]</smiles>

21

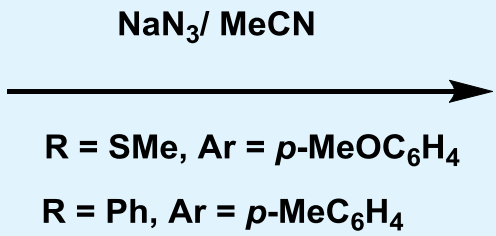

$\mathrm{R}=\mathrm{Ph}, \mathrm{Ar}=p-\mathrm{MeC}_{6} \mathrm{H}_{4}$

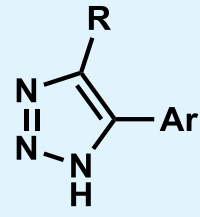

22

Scheme 7: Reactions of isothiazoles from 21 to 22.

The cyclic sulfonamides or sultams 23 reacts with oxygen nucleophiles would be expected to occur through attacking at C-5 by a Michael type reaction and give the product of 4,5-dihydrosultams 24 as two isomers where trans isomer is major and cis is minor (Scheme 8).

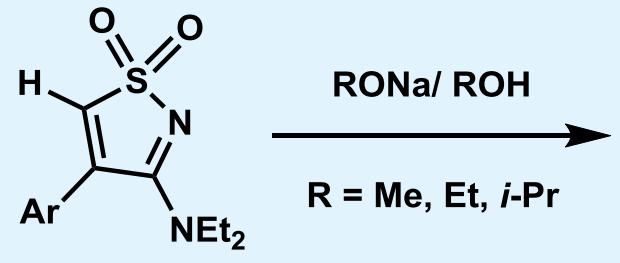

23

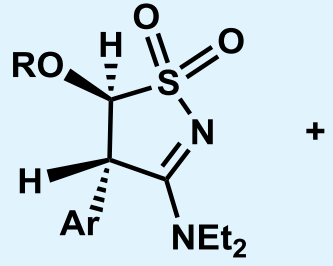

24-(trans)

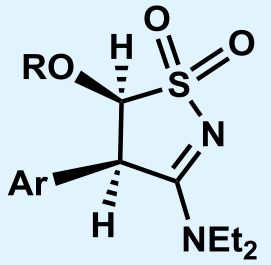

24-(cis)

Scheme 8: Reaction of sultams A with oxygen nucleophiles to afford B.

\section{Pharmaceutical and Medicinal Importance of Isothiazoles}

\section{Pharmaceutical Importance}

The main aim of this study was to investigate the synthesis, reactions and pharmaceutical importance of isothiazoles and their derivatives. The different derivatives of isothiazole displayed a remarkable antiviral, anti-inflammatory and immunotropic actions. Isothiazoles fused to benzene ring is known to be present in drugs such as antipsychotic drugs, Geodon [33] and Perispirone [34]. Penicillins and cephalosporins which 
contain isothiazole moiety competed successfully with ampicillin with regards to their activity against gram positive and gram-negative bacteria [35]. Also, many isothiazole derivatives were useful in the treatment of Alzheimer's disease, as anti-inflammatory, anticonvulsant drugs and serine protease inhibitors [36]. They are also known to possess histone acetyl transferase inhibitors [37], and carrageenan-induced edema inhibitory activity [38].

\section{Isothiazoles as Antiviral, Anti-Inflammatory Properties and Immunotropic Actions}

Isothiazoles types of compounds show a great activity against antiviral, inflammatory properties. The synthesis of 5-(4-chlorobenzoyl) amino-3-methyl-4isothiazolecarboxylic acid derivatives has been reported by the researcher Regiec, et al. which exhibited good antiinflammatory properties. That means the different derivatives of 5-amino-3-methyl-4-isothiazolecarboxylic acid 25 showed a noteworthy antiviral, anti-inflammatory and immunotropic action which is recently discovered $[39,40]$. Till date, the 5-N-benzoyl series of this amino acid 26 has been widely studied [41]. From the series of compounds, 5-benzoylamino-N-(4-ethoxyphenyl)-3methyl-4-isothiazolecarboxamide (ITF) 27 exhibited a significant anti-inflammatory and broad antiviral activity which was both in vitro and in animal models [42]. And same result was true for 5-benzoylamine-N-(4chlorophenyl)-3-methyl-4-isothiazolecarboxamide 28, which is known as denotivir (ITCL, vratizolin) [43]. And it is the antiviral drug with anti-inflammatory activity used mainly against herpes virus infections. It is notable that this is only for external application because of its poor bioavailability after gastric administration [44-49]. The denotivir has also the immunotropic activity (Figure 2).

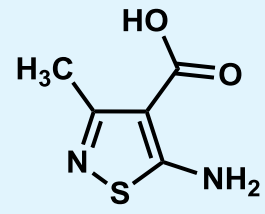

25

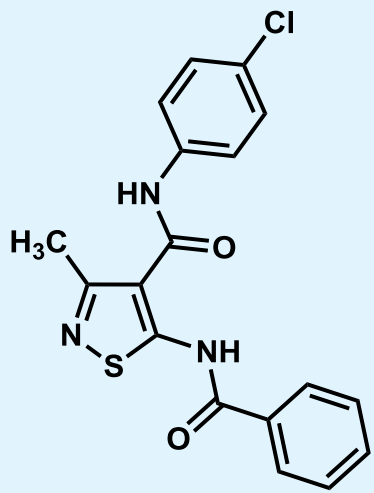

ITF 27<smiles>Cc1nsc(NC(=O)c2ccccc2)c1C(=O)O</smiles>

26

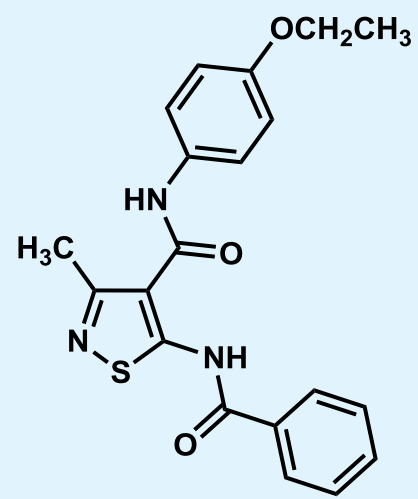

Denotivir 28

Figure 2: Isothiazole derivatives which act as antiviral, anti-inflammatory and immunotropic properties.

\section{Medicinal Importance}

A sulfur-containing five-membered ring compound is a partial structure contained in many pharmacological activities, physiologically active substances, and many bioactive organic compounds having an isothiazole ring have been reported so far. For example, Lu et al. synthesized the JE-2147 derivative 30 having HIV protease inhibitory activity $[50,51]$, by Yao, et al. synthesized isothiazole derivative 33 [52] having HCV NS5B polymerase inhibitory activity, synthesized the viral 


\section{Medicinal \& Analytical Chemistry International Journal}

herpes simplex synthetically 2'-dioxy-5-(isothiazol-5-yl) uridine 29 having virus (HSV-1) kinase inhibitory activity, by Carlessi, et al. reported the VRX 046661731 having selective Chk2 inhibitory activity [53]. And Beebe, et al. synthesized and reported the VEGFR-2 inhibitory activity inhibitor CP-547,632 32 (Figure 3) [54].

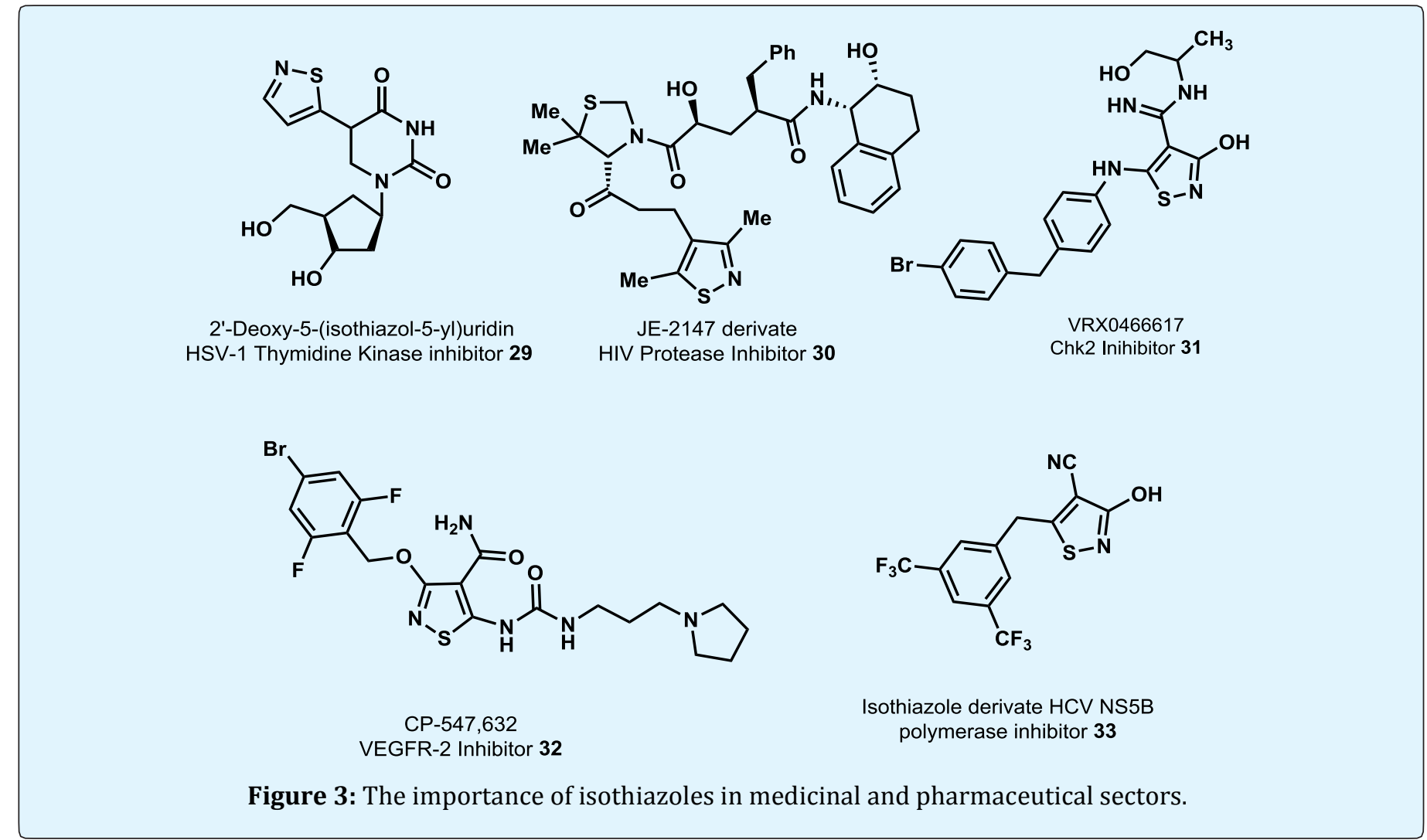

Few derivatives of 5-substituted 3-methyl-4isothiazolecarboxylic acid and the synthesized derivatives were checked for humoral immune response and also checked for delayed type hypersensitivity reaction through in-vivo method using sheep red blood cells by Lipnicka, et al. [55] 34 which exhibited a good result (Figure 4).

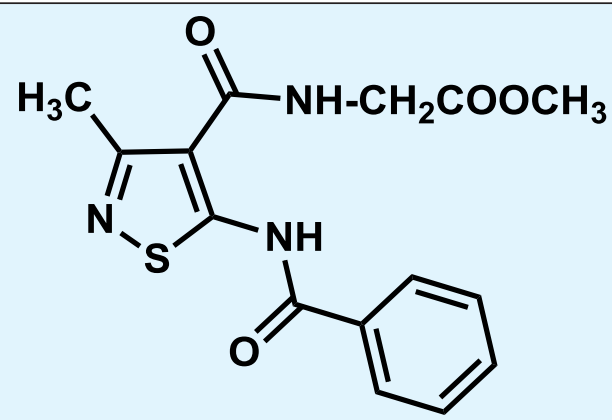

34

Figure 4: Compound 34 used for humoral immune response and delayed type hypersensitivity reaction.
The synthesis of the partial GABAA agonist thio-4PIOL 35 (Figure 5) through the usage of different substituents have been reported by Krehan, et al. and the effect of each substituent on the activity were also studied and found good [56].<smiles>Cc1ccc(Cc2c(O)nsc2C2CCNCC2)cc1</smiles>

Figure 5: The synthesis of the partial GABAA agonist thio-4-PIOL through the usage of different substituents. 
The synthesis of 6-methyl-9- $\alpha$-D-ribofuranosylpurine and imidazo [4,5-d]isothiazole derivatives have been reported by Swayze and his co-workers [57] and 36 exhibited moderate inhibition of L1210 cell growth (Figure 6).

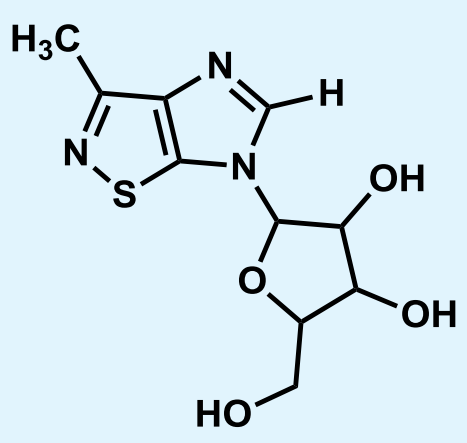

36

Figure 6: The compound which exhibited moderate inhibition of L1210 cell growth.

The acetic acid derivatives of naphtha [1,2d]isothiazole (NiT) were synthesized by Settimo, et al. [58] and the synthesized derivatives were tested and found as novel aldose reductase (ALR2) inhibitors. And it was proved to be effective against cataract development in galactosemic rats by the compound 37 (Figure 7).

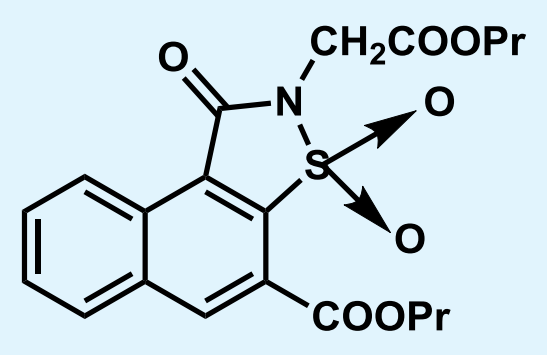

37

Figure 7: The compound 37 uses as novel aldose reductase (ALR2) inhibitors.

\section{Some Other Importance of Isothiazoles}

Isothiazoles and their derivatives have also been used in color photography for the stabilization of photomaterials, detergents, waste decontamination, corrosion inhibition [59] and in antifreeze compositions in diesel engines [60]. There are many other references in the articles and patent literature regarding the importance of isothiazoles like preparation of azo dyes from aminoisothiazole and 1,2-benzisothiazole derivatives. These are very much essential in the synthetic fiber dying sectors. Furthermore, the 4cyanoisothiazole derivatives are used to prepare the inkjet inks and dyes [61]. It was also reported that the isothiazoline-type compounds are used as wood preservative $[62,63]$. So, it can be summarized that the isothiazoles are so much useful either as synthetic intermediates or in biological and industrial purposes.

\section{Conclusion}

Here, the authors reported a brief review on the synthesis, reactions and biological importance of the different type of isothiazoles and their derivatives. Isothiazoles and their derivatives have the vast applications in biological, pharmaceutical, medicinal and in many other fields. Authors believe that the researchers including chemists, biologists and pharmacists will take this review study as one of their desirable and valuable materials for undergoing the works on isothiazoles and their derivatives.

\section{References}

1. Chapman RF, Peart BJ (1996) 3.05 - Isothiazoles. Comprehensive Heterocyclic Chemistry II 3: 319-372.

2. Pain DL, Peart BJ, Wooldridge KRH (1984) Isothiazoles and their Benzo Derivatives. Comprehensive Heterocyclic Chemistry 6: 131-175.

3. Bird CW, Cheseman GWH (1984) Chapter 4.17. In: (Eds.) Pergamon: Oxford, 6: 131-175.

4. Adams A, Slask R (1956) Chem Ind (London) 42: 1232.

5. Grimmett MR, Iddon B (1995) Synthesis and Reactions of Lithiated Monocyclic Azoles Containing Two or More Hetero-atoms. Part VI: Triazoles, Tetrazoles, Oxadiazoles, and Thiadiazoles. Heterocycles 41(7): 1525-1574.

6. Iddon B (1995) Synthesis and Reactions of Lithiated Monocyclic Azoles Containing Two or More HeteroAtoms. Part V: Isothiazoles and Thiazoles. Heterocycles 41(3): 533-593.

7. Iddon B, Ngochindo RI (1994) Synthesis and Reactions of Lithiated Monocyclic Azoles Containing 


\section{Medicinal \& Analytical Chemistry International Journal}

Two or More Hetero-Atoms Part IV: Imidazoles. Heterocycles 38(11): 2487-2568.

8. Iddon B (1994) Synthesis and Reactions of Lithiated Monocyclic Azoles Containing Two or More HeteroAtoms. Part I: Isoxazoles. Heterocycles 37(2): 12631320.

9. Suschitzky H, Scriven EFV (1992) Prog Heterocycl Chem 4: 295.

10. Suschitzky H, Scriven EFV (1993) Prog Heterocycl Chem 5: 341 .

11. Giorgi G, Salvini L (1999) Targets Heterocycl Syst 3: 369-398.

12. Schulze B, Mutze K, Selke D, Kempe R (1993) Tetrahedron Lett 34(12): 1909-1912.

13. Bradley PA, Wilkins DJ (1999) Prog Heterocycl Chem 11: 184-199.

14. Capperucci A, Degl'Innocenti A, Scafato P (1998) Recent Res Dev Synth Org Chem 1: 171-197.

15. Giorgi G (1998) Targets Heterocycl Syst 2: 471-496.

16. Tanaka R, Shinkai I (1992) Prog Heterocycl Chem 4: 123-137.

17. Tanaka R, Shinkai I (1993) Prog Heterocycl Chem 5: 159-172.

18. Bradley PA, Wilkins DJ (1998) Prog Heterocycl Chem 10: $172-194$.

19. Alan RA, Tracy M (1998) Prog Heterocycl Chem 10: 195-208.

20. Kaberdin RV, Potkin VI (2002) Isothiazoles (1,2thiazoles): synthesis, properties and applications. Russian Chemical Reviews 71(8): 673-694.

21. Clerici F (2002) Thiazole and thiadiazole S-oxides. Adv Heterocycl Chem 83: 71-115.

22. Dissertation: Duncan K (1988) Ann Dis Abstr 48(9): 2648.

23. DeglInnocenti A, Capperucci A (1998) Organosilanes in Sulfur Chemistry: Silicon Mediated Synthesis and Reactivity of Sulfur-Containing Molecules. Sulfur Rep 20(3): 279-395.
24. Elgazwy ASSH (2003) The chemistry of isothiazoles. Tetrahedron 59(38): 7445-7463.

25. Adams A, Slask R (1956) Chem Ind (London) 42: 1232.

26. Adams A, Slack R (1959) Isothiazole: a new mononuclear heterocyclic system. J Chem Soc 30613072.

27. Bridson JN, Copp SB, Schriver MJ, Zhu SG, Zaworotko MJ (1994) The preparation of 1,2,3,5-dithiadiazolium chlorides from the reaction of nitrile sulphides with thiazyl chloride. Can J Chem 72(4): 1143-1153.

28. Duan XG, Duan XL, Rees CWJ (1997) Chem Soc Perkin Trans 1: 2831

29. Schulze B, Dietrich U, Illgen K J Siler (1994) Zh Org Khim 30: 1379.

30. Schulze B, Kirsten G, Kirrbach S, Rahm A, Heimgartner H (1991) Zur Oxidation von 1,2-Thiazolen: Ein einfacher Zugang zu 1,2-Thiazol-3(2H)-on-1,1-dioxiden. Helv Chim Acta 74(5): 1059-1070.

31. Bhavana S, Hastak B, Ghiya J (1992) Ind J Heterocycl Chem 2: 133.

32. Capuano L, Hammerer V, Huch V Liebigs (1994) Ann Chem 23.

33. Howard HR, Lowe JA III, Seeger TF, Seymour PA, Zorn $\mathrm{SH}$, et al. (1996) 3-Benzisothiazolylpiperazine Derivatives as Potential Atypical Antipsychotic Agents. J Med Chem 39(1): 143-148.

34. Matsushita $M$, Egashira N, Harada S, Okuno R, Mishima K, et al. (2005) Perospirone, a Novel Antipsychotic Drug, Inhibits Marble-Burying Behavior via 5-HT1A Receptor in Mice: Implications for Obsessive-Compulsive Disorder. J Pharmacol Sci 99(2): 154-159.

35. Shiwa T, Amano T, Matsubayashi H, Seki T, Sasa M, et al. (2003) Perospirone, a Novel Antipsychotic Agent, Hyperpolarizes Rat Dorsal Raphe Neurons via 5HT1A Receptor. J Pharmacol Sci 93(1): 114-117.

36. Raap R, Micetich RG (1968) Penicillins and cephalosporins from isothiazolylacetic acids. J Med Chem 11(1): 70-73. 


\section{Medicinal \& Analytical Chemistry International Journal}

37. Frija LMT, Pombeiro AJL, Kopylovich MN (2016) Coordination chemistry of thiazoles, isothiazoles and thiadiazoles. Coordination Chemistry Reviews 308(1): 32-55.

38. Stimson L, Rowlands MG, Newbatt YM, Smith NF, Raynaud FI, et al. (2005) Isothiazolones as inhibitors of PCAF and p300 histone acetyltransferase activity. Mol Cancer Ther 4(10): 1521-1532.

39. Regiec A, Machon Z, Miedzybrodzki R, Szymaniec S (2006) New Isothiazole Derivatives: Synthesis, Reactivity, Physicochemical Properties and Pharmacological Activity. Arch Pharm 339(7): 401413.

40. Machon Z (1988) Drugs Future 13(5): 426-428 and the references cited there.

41. WHO (1993) Drug Inform 7(4): 206.

42. Regiec A (1998) Dissertation (in Polish), Faculty of Pharmacy, Wrocław Medical University, and unpublished data.

43. Machon Z, Regiec A, Wieczorek Z, Potrykus A, Przybylski F (1999) Register no. of patent notification 331778. Biuletyn Urzedu Patentowego (Bulletin of the Polish Patent Office (in Polish)), 18 (670) Rok XXVII.

44. Machon Z, Wieczorek Z, Zimecki M (2001) Immunotropic activity of vratizolin (ITCL, Denotivir). Pol J Pharmacol 53(4): 377-383.

45. Miedzybrodzki R (2003) Dissertation (in Polish), Institute of Immunology and Experimental Therapy, Polish Academy of Sciences.

46. Urszula L, Andrzej R, Emil S, Michał Z (2005) New Amides of 5-Acylamino-3-Methyl-4-Isothiazolecarboxylic Acid and their Immunotropic Activity. Arch Pharm Chem Life Sci 338(7): 322-328.

47. Rostkowska B, Pospiech L, Jankowska M (1993) Arch Immunol Ther Exp 41: 137-140.

48. Prandota J, Wilimowski $\mathrm{M}$, Inglot $\mathrm{AD}$, Machon $\mathrm{Z}$ (1973) ibid 21: 915-923.

49. Giełdanowski J, St. H. Kowalczyk-Bronisz, Machon Z, Szary A, Błaszczyk B (1980) ibid 28: 393-407.
50. Regiec A, Machon Z, Mie،dzybrodzki R, Szymaniec S (2006) New Isothiazole Derivatives: Synthesis, Reactivity, Physicochemical Properties and Pharmacological Activity. Arch Pharm Chem Life Sci 339(7): 401-413.

51. Lu Z, Raghavan S, Bohn J, Charest M, Stahlhut MW, et al. (2003) Design and synthesis of highly potent HIV protease inhibitors with activity against resistant virus. Bioorg Med Chem Lett 13(10): 1821-1824.

52. Yao N, Yan S, Appleby T, Gunic E, Shim JH, et al. (2007) Isothiazoles as active-site inhibitors of HCV NS5B polymerase. Bioorg Med Chem Lett 17(1): 2833.

53. Carlessi L, Buscemi G, Larson G, Hong Z, Wu JZ, et al. (2007) Biochemical and cellular characterization of VRX0466617, a novel and selective inhibitor for the checkpoint kinase Chk2. Mol Cancer Ther 6(3): 935944.

54. Beebe J, Jani JP, Knauth E, Goodwin P, Higdon C, et al. (2003) Pharmacological Characterization of CP547,632, a Novel Vascular Endothelial Growth Factor Receptor-2 Tyrosine Kinase Inhibitor for Cancer Therapy. Cancer Res 63(21): 7301-7309.

55. Lipnicka U, Regiec A, Sułkowski E, Zimecki M (2005) New Amides of 5-Acylamino-3-Methyl-4-Isothiazolecarboxylic Acid and their Immunotropic Activity. Arch Pharm Chem Life Sci 338(7): 322-328.

56. Dorte K, Signe IS, Tommy L, Bjarke E, Birgitte N, et al. (2006) Potent 4-Arylalkyl-Substituted 3-Isothiazolol GABAA Competitive/Noncompetitive Antagonists: Synthesis and Pharmacology. J Med Chem 49(4): 1388-1396.

57. Swayze EE, Drach JC, Wotring LL, Townsend LB (1997) Synthesis, Antiproliferative and Antiviral Activity of Imidazo [4,5-d] isothiazole Nucleosides as 5:5 Fused Analogs of Nebularine and 6-Methylpurine Ribonucleoside. J Med Chem 40(5): 771-784.

58. Settimo FD, Primofiore G, Motta CL, Sartini S, Taliani S, et al. (2005) Naphtho [1,2-d] isothiazole Acetic Acid Derivatives as a Novel Class of Selective Aldose Reductase Inhibitors. J Med Chem 48(22): 6897-6907.

59. Pasch NF, US, Patent 6,068,879, 9 pp, 76. 
60. Kaberdin RV, Potkin VI (2002) Isothiazoles (1,2thiazoles): synthesis, properties and applications. Russ Chem Rev 71(8): 673.

61. Turcotte DE, Coffey ALJ, Olsen AW, Dituro MA, Stephens CR, US Patent US US 6, 290, 870, 11pp. (Chem. Abstr.; 2001, 135, 244824u).
62. Bradbury R, Moscrop C, Meyrick BH, Holbrook MB, Br UK Patent Appl 2,335,924, pp: 31.

63. Abe, Akira Jpn Patent 10, 43, 323, 805, pp: 98, 323, 805. 